\title{
STATEMENT ON PERSONAL PROTECTIVE MEASURES TO PREVENT ARTHROPOD BITES
}

\section{Preamble}

The Committee to Advise on Tropical Medicine and Travel (CATMAT) provides the Public Health Agency of Canada (PHAC) with ongoing and timely medical, scientific, and public health advice relating to tropical infectious disease and health risks associated with international travel. The Agency acknowledges that the advice and recommendations set out in this statement are based upon the best current available scientific knowledge and medical practices, and is disseminating this document for information purposes to both travellers and the medical community caring for travellers.

Persons administering or using drugs, vaccines, or other products should also be aware of the contents of the product monograph(s) or other similarly approved standards or instructions for use. Recommendations for use and other information set out herein may differ from that in the product monograph(s) or other similarly approved standards or instructions for use by the licensed manufacturer(s). Manufacturers have sought approval and provided evidence as to the safety and efficacy of their products only when used in accordance with the product monographs or other similarly approved standards or instructions for use.

Members: Dr. A. McCarthy (Chair); Dr. A.K. Boggild; Dr. J. Brophy; Dr. Y. Bui; Dr. C. Greenaway; Dr. M. Crockett; Dr. W. Ghesquiere; Ms. A. Henteleff; Dr. M. Libman; Dr. K.L. McClean; Dr. P.J. Plourde; Dr. P. Teitelbaum.

Ex-Officio Representatives: Dr. P. Charlebois; Dr. P. McDonald; Dr. S. Schofield; Dr. M. Tepper.

Liaison Representatives: Dr. G. Brunette; Dr. C. Hui.

Member Emeritus: Dr. C.W.L. Jeanes.

†This statement was prepared by S. Schofield and P. Plourde and approved by CATMAT.

CATMAT gratefully acknowledges the Pest Management Regulatory Agency, the World Health Organization Pesticide Evaluation Scheme (WHOPES) and the Armed Forces Pest Management Board for contributing to the development of the statement. 


\section{Introduction}

A variety of pathogens are transmitted to humans by arthropod vectors, including some that cause important travel-related diseases (e.g., malaria and dengue). Typically, though not always (e.g., Chagas disease and louse-borne typhus), transmission is through the bite of a vector, with the offending pathogens generally completing a portion of their lifecycle within the arthropod.

While mosquitoes are the most notorious and important vector of arthropod-associated diseases (AAD), there are many other arthropods capable of transmitting pathogens (e.g., ticks, sandflies, tabanids, lice, mites, fleas, tsetse flies and reduviid bugs) (see Appendix 1). This diversity can make prevention and treatment of AAD challenging because not only are there many diseases of concern, the range of vectors is vast, as are the associated behaviours and epidemiologies. This complexity is well-illustrated by contrasting two groups of mosquitoes, Aedes and Anopheles, respectively the genera responsible for transmission of dengue and malaria. While these groups of mosquitoes might look somewhat similar, they diverged from each other more than 100 million years ago (1), and hence have had substantial time to develop different life-history strategies. Thus, on one hand, there is Aedes aegypti, the principal vector of dengue (2) which typically lives in and around developed areas and generally bites during daylight hours, albeit more often in the morning or towards evening. On the other hand, there is Anopheles gambiae s.s., found in Africa and the world's most efficient vector of malaria. This species is primarily found in rural areas and tends to bite inside and during the hours of

\section{Personal protective measures}

Considering the substantial diversity among vectors, it is striking that a single approach (i.e., bite prevention) works for all of the different genera, and further that a small suite of interventions (i.e. personal protective measures [PPM]) show broad utility in this regard. This is in marked contrast to other preventive medical interventions such as vaccines and chemoprophylactic drugs where effectiveness is often limited to a particular pathogen to prevent a specific disease.

This statement provides guidance and recommendations on the use of PPM to prevent arthropod bites. These interventions have a long history of use in traditional societies (6;7), with modern approaches to research, development and discovery evolving over the last century, often as a result of military-sponsored innovation (8). darkness. While both species feed on human hosts and transmit important pathogens, it is their differences that are relevant with respect to the when and the where of disease threat. Such diversity is not limited to disparate genera of mosquitoes or classes of insect. Indeed, even among the forty or so important species of malaria vectors (3), there are significant and intervention-relevant differences in behaviour and biology. For example, the aforementioned A. gambiae s.s. tends to be endophagic, that is, it bites inside buildings. This predilection, combined with its nighttime habits, means that bed nets are a critical intervention (4). In contrast, A. albimanus, an important vector in the Americas, often bites outside and earlier in the evening, before people sleep. Hence, bed nets, while still important, are likely relatively less so for protection against this species, at least compared against topical repellents and appropriate clothing. Complicating matters for this latter species are data that suggest that it has enhanced "tolerance" to the insect repellent DEET (N,N-diethyl-3-methyl- benzamide, also known as $\mathrm{N}, \mathrm{N}$-diethyl-m-toluamide) such that duration of protection is shortened (5).

The important take-home message for the clinician and traveller is that significant variability exists among vectors and, wherever possible, preventive approaches should be sufficiently flexible to take account of this. This could be as simple as re-applying repellent when bites are noted instead of strictly adhering to label-indicated protection times, or using a bed net whenever resting, regardless of the time of day.

While many different types of PPM likely have some protective benefit (9), this statement will concentrate on physical (e.g., clothing, bed nets) and chemical (e.g., topical repellents and bed net treatments) barriers. This emphasis reflects, firstly, a strategy to manage the level of guideline development effort required, and secondly the committee's belief that the focus was best directed at PPM for which:

- use is primarily under the control of the individual traveller;

- access is possible in/from Canada; and

- relevant, robust and contemporary data are available by which benefits and harms can be judged (e.g., repellents and insecticides). 


\section{Evaluation of evidence and recommendations}

Evidence was evaluated as per the 1994 CATMAT statement on evidence-based medicine (EBM) (Appendix 2) (10). CATMAT makes the following points related to this review process:

- a systematic collection and review of evidence was not performed. Rather, the evidence collected and evaluated to develop the 2005 statement (11) was updated by conducting literature searches using PubMed. The search terms were "repellent" or "bed net" or "personal protection" alone, or in combination with "traveller". Searches were limited to articles published since 2005. The authors also screened the entomological literature, first by entering the same search terms into the literature retrieval system of the Armed Forces Pest Management Board (12), and second by identifying other published and non-published information, in particular through conversation with national pesticide regulatory authorities. Specific inclusion criteria were not used, rather relevancy was subjectively assigned on the bases of novelty (e.g., a new approach that has become available since 2005), and robustness (e.g., randomized trials and/or traveller-relevant endpoints).

- while CATMAT recognizes that well-executed randomized studies with travellers would provide the highest quality of evidence for PPM, these are lacking. There have been, however, a number of randomized studies carried out with PPM (especially bed nets) in endemic areas with resident populations. Although it can be argued that indirectness reduces the quality of these data when applied to travellers (13), CATMAT feels they can still yield strong recommendations, especially if relevant endpoints (e.g., prevention of clinical disease) and populations (e.g., all ages) are used, and/or where the magnitude of effect is large and consistent (14).

- CATMAT has high confidence that the risk-based pesticide regulatory systems of Canada and the United States are robust and conservative $(15 ; 16)$. This reflects the emphasis, on the part of regulators, on product safety wherein multiple and multiplicative safety factors are employed. Hence, PPM products approved by these systems are considered to have excellent safety profiles and are unlikely to present risks that are relevant to health-based decision-making.
- CATMAT notes that much of the evidence concerning repellents comes from relatively small-scale entomological studies in which protection against bites rather than against disease was the outcome of interest. Individually, such studies are not considered to provide a high quality of evidence regarding disease prevention. However, CATMAT does consider protection against bites to be a reasonable, albeit indirect, proxy for protection against clinical disease. Hence, where there is consistency in outcome(s) across studies and if the estimated effect is large, CATMAT considers that the aggregate result is sufficient to make a strong recommendation for use.

- CATMAT appreciates that there are a myriad of possible vector-disease combinations, and that the majority of these have not been subjected to significant inquiry regarding the protective utility of PPM. Rather, analytic emphasis and consequently evidence has been principally on/for mosquitoes and PPM. For other vectors (e.g., ticks, tsetse flies, sandflies) there is less evidence, but what is available generally supports that the PPM that work against mosquitoes also work against these groups. Hence, recommendations made herein are principally based on mosquito-derived evidence, but are considered to be generally applicable to arthropod vectors. A systematic vector-by-vector evaluation of PPM utility was not done.

- CATMAT's perspective for analysis is that of the traveller. In general, this simplifies matters as indirect and longer term effects of PPM on human and vector populations at the community level need not be considered. On the other hand, it can amplify concerns associated with vector-based variability. For example, resistance among malaria vectors to the pyrethroid insecticides that are used to treat bed nets has been documented in parts of Africa, although it remains unclear what the impact of such resistance will be at the community level $(17 ; 18)$. However, because insecticide resistance seems to be associated with an increased probability that mosquitoes will bite "through" a treated net, it likely attenuates bed net utility at the individual (including traveller) level.

- Appendix 3 provides a summary of all recommendations made in this statement. 


\section{Recommendations for personal protection}

If insects cannot bite, they cannot transmit pathogens. It follows that reducing exposure to arthropods, whether by avoidance or by reducing access to skin through use of barriers, can prevent AAD. These tactics are complimentary and should be used in concert. Importantly, PPM are intended to augment, not replace the use of appropriate

\section{Avoiding arthropods}

There are several ways by which arthropods can be avoided, and it seems self-evident that these should reduce the risk of acquisition of AAD. However, there is little direct scientific evidence to support this supposition. Despite these evidentiary shortcomings, CATMAT believes that the following avoidance measures are likely to have some utility and further, because their use is unlikely to present a risk, that they should be undertaken when/ where possible.

1. Avoid travelling to risk areas during the season(s) when transmission of AAD is most likely.

2. Reduce exposure by avoiding times or places when/ where vectors are known to be active (e.g., by staying indoors during peak activity periods, minimizing exposure in rural areas or other habitats associated with specific vectors).

\section{PHYSICAL BARRIERS}

There are a variety of physical barriers that can be used to reduce contact between vectors and their human hosts. Some are easily implemented at the time of exposure (e.g., wearing of appropriate clothing, using of mosquito netting), whereas others, such as window and door screening, air conditioning and closed eaves might require advance planning to ensure that they are available. CATMAT makes the following recommendations related to the use of physical barriers:

\section{Protect work and accommodation areas against}

vectors. This can be achieved by use of screening on doors and windows, closing eaves, eliminating holes in roofs and walls and closing other gaps around a building. These interventions have been linked to historical reductions of malaria risk in North America and Europe $(20 ; 21)$ and were associated with reduced entry of malarious mosquitoes into huts and lower levels of anemia in hut occupants, in a recent randomized trial in Africa using intention-to-treat analysis (22). Several medications and vaccines (e.g., malaria chemoprophylaxis for prevention of malaria) (19). Of course, this point presupposes the availability of medications and/or vaccines which, for many AAD (e.g., dengue, leishmaniasis), do not exist, i.e. PPM often are the only tactic available for risk reduction.

other smaller-scale trials in Africa also have demonstrated that house "screening", including the closing of eaves, can significantly reduce the number of malaria mosquitoes entering buildings (23).

2. Use bed nets. CATMAT recommends use of insecticidetreated bed nets (ITN), though there is evidence that untreated nets can provide substantial protection against the bites of mosquitoes and other arthropods. Bed nets, treated or untreated, also are thought to act as a barrier against other animals (e.g., bed bugs, rodents and scorpions), and there are data suggesting that they can reduce the risk of bites from venomous snakes (24).

3. Wear appropriate clothing. There is entomological literature demonstrating that covering skin with cloth can reduce mosquito biting (25), though efficacy is affected by: the type of fabric; the number of fabric layers present; and weave. There also are data to suggest that clothing can be protective against malaria $(26 ; 27)$, though their quality is rather poor. Despite such limited evidence, CATMAT recommends that appropriate clothing (full length, loose fitting, light coloured) be worn appropriately (sleeves rolled down, pants tucked in) to protect against arthropod bites. This position reflects the integration of three factors: first, there is some entomologic and observational evidence to support this intervention, and it is plausible from a mechanistic perspective; second, it seems unlikely that wearing appropriate clothing presents any risk relevant to health-based decision-making; and third, wearing such clothing might offer added benefits such as sun protection.

Of note, light-coloured clothing is thought to help wearers spot and remove ticks before they are able to bite $(28 ; 29)$.

\section{CHEMICAL BARRIERS}

Though somewhat arbitrary, we differentiate between two types of chemical barrier: repellents, usually topical, which have as a primary effect the prevention of insects and other 
arthropods from biting; and insecticides which generally kill insects and other arthropods upon contact or soon thereafter. In reality, there can be overlap in activity, with insecticides sometimes also acting as repellents (e.g., permethrin) and with some topical repellents showing toxicant properties (e.g., DEET).

\section{Topical repellents}

Application of topical repellents to exposed areas of skin prevents arthropods from biting, but does not necessarily prevent their approach towards the host. Though used for thousands of years $(6 ; 7)$, science-based repellent evaluation and development has primarily been during the last century. Further, it only has been very recently that the mode of action of DEET and its analogues has started to be elucidated (30-32), with these compounds apparently having a direct effect on insect sensilla. Concurrent with these efforts has been a veritable explosion of investigations into novel repellent products, in particular "natural" compounds (7). That naturally-derived repellents exist is hardly surprising given the multitude of plantderived chemicals that target insects. Indeed, it has been postulated that the sensitivity of haematophagous arthropods to some of these compounds represents an evolutionary relic of their plant feeding past (7). However, despite some success at commercialization, there are few registered natural repellent products available on the North American market. Further, several authors have cautioned against the dangerous generalization that natural equals safe $(6 ; 7)$, i.e. there is no a priori reason to expect that unregistered natural repellents are safe or effective. Hence, CATMAT recommends against use of unregistered "natural" (or other) topical repellents to protect against the bites of mosquitoes and other arthropods.

Topical and other repellents (and insecticide barriers, see below) must be reviewed for efficacy and safety by Health Canada's Pest Management Regulatory Agency (PMRA) before they can be sold and used in Canada. There is a similar requirement in the United States (US), where the Environmental Protection Agency (EPA) has responsibility for product registration. For both agencies, emphasis is placed on product safety. Efficacy is also considered, though the relevant endpoints (33) are intended to meet regulatory needs and hence can at best be considered indirect measures in a disease protection context. Nevertheless, the evidence that repellents prevent the bites of insects and other arthropods is overwhelming and generally consistent, and CATMAT considers that there is a very high probability that prevention of bites will reduce exposure to arthropod-associated pathogens. Further, there is direct evidence from a randomized trial that use of a topical repellent can reduce the incidence of malaria amongst residents in an endemic setting (34).

CATMAT makes the following recommendations related to use of topical repellents:

1. Use topical repellent on exposed areas of skin to prevent arthropod bites and to reduce the risk of AAD.

2. Five active ingredients are currently registered in Canada: DEET, icaridin (also called picardin or KBR 3023), p-menthane-3,8-diol (PMD), soybean oil and citronella. Of these, DEET has the longest history of use and has consistently demonstrated a high level of efficacy. Icaridin (1-piperidinecarboxylic acid 2-(2-hydroxyethyl)-1-methylpropylester), approved for use in Canada in 2012, demonstrates levels of efficacy similar to DEET, has been available in other jurisdictions for some time and is recommended by the United States Centres for Disease Control and Prevention (US CDC) $(35 ; 36)$ for protection against the bites of mosquito vectors. Further, it has been evaluated by the World Health Organization's Pesticide Evaluation Scheme (WHOPES) $(37 ; 38)$ which recommends it as a "safe and effective insect repellent for human use". Based on these traits, DEET and icaridin are recommended as the first choice topical repellents for protection against arthropod bites and AAD. Use of topical repellents containing PMD have been shown to prevent malaria (34) and are recommended by the US $\operatorname{CDC}(35 ; 36)$ for protection against the bites of mosquito vectors. However, products currently available in Canada contain no more than 10\% PMD and are not considered to provide the same duration of protection afforded by higher concentrations of DEET and icaridin. Additionally, use of PMD-containing repellents is restricted to persons three years of age and older. For these reasons, products containing PMD should be considered as a second choice for use by Canadian travellers. Other active ingredients currently registered as topical repellents in Canada (e.g., citronella, soybean oil), are not widely available and/or do not provide sufficiently long protection times against bites $(39 ; 40)$, and are not recommended for use to protect travellers against the bites of vectors.

3. In general, as the concentration of DEET (Appendix 4) or icaridin increases so too does the period of bite protection. Currently, the maximum concentrations permitted for adult (civilian) use in Canada are: $30 \%$ DEET plus active related toluamides, or $20 \%$ icaridin. CATMAT believes that higher concentration products offer an advantage in that they need not be reapplied 
as frequently, and therefore recommends that adults use products that contain $20 \%$ or more DEET or $20 \%$ icaridin. For children, the PMRA currently permits use of up to 10\% DEET three times daily for those aged two to 12 years and once a day for children aged six months to two years. By contrast, children aged six months or older are permitted to use up to $20 \%$ icaridin. Hence, icaridin is the preferred repellent for this age category, with DEET as a second choice. The PMRA does not permit use of DEET or icaridin on infants under the age of six months (41) (Icaridin Registration Decision Document). CATMAT acknowledges these regulations, but points out that they were not developed to prevent $A A D$, but rather reflect regulatory decision-making based on the Canadian context of prevention of nuisance biting. For this reason, CATMAT believes that, for travel outside of Canada where $A A D$ are endemic/epidemic and where exposure is likely, the risk for AAD likely outweighs the risk of an adverse reaction to DEET or icaridin. In such situations and if vectors cannot be otherwise excluded (e.g., through use of insecticide-treated netting), use of up to 10\% DEET or icaridin should be considered for infants under six months of age. Product should be applied as per label directions for infants $>$ six months of age.

4. Reapply repellent when required. The labels of topical repellents often provide protection time estimates, for example "protects against mosquitoes for six hours". These values, while based on evaluation of efficacy data, are not developed against the backdrop of AAD risk, and further do not sufficiently account for variation based on factors such as sweating (42), species of mosquito (43) and numbers of mosquitoes (44). Thus, for travel outside of Canada to areas where AAD is a threat, repellent might reasonably be applied more frequently than is indicated on the label. As a general rule, if biting is noted before the interval on the label has expired, then reapplication of repellent is recommended. If there is a desire to minimize use of repellent, treatment can be timed so as to optimize protection with a minimum number of applications. For example, applying a long-lasting formulation before or immediately after exiting a treated bed net in the morning and applying it again in the late afternoon to cover the period from dinner until entry into a treated bed net would likely offer protection during the period of higher activity for many malaria vectors.

5. Uptake of PPM can be poor among travellers (45-47). Though there is little data that evaluates interventions targeting increased compliance, it is plausible that individual preferences might positively influence adherence. For this reason, CATMAT encourages practitioners and travellers to tailor repellent recommendations/choices to individual preference(s) (e.g. some persons might prefer a cream repellent product, others a liquid and others a spray).

6. The use of repellent and sunscreen combination products is not supported by the PMRA, and also is not recommended by CATMAT. This partly reflects that directions for use of these products are somewhat at odds - sunscreens are to be applied often and liberally, whereas repellents should be applied less liberally and less often. There also is evidence that co-administration can reduce the performance of sunscreen and conversely that it can enhance percutaneous absorption of DEET (48-52), though this might not be the case with icaridin (50). Because interaction between sunscreen and repellent are likely to decrease with the interval between their respective applications, it is recommended that, if both are required, sunscreen be applied first and allowed to penetrate the skin (e.g., for 15 minutes) before applying repellent. Where this is not possible, CATMAT considers that the protective utility of these interventions outweigh any risks that their coadministration might pose, i.e. application of both is recommended even if sunscreen cannot be applied before repellent.

\section{Insecticide barriers}

A variety of insecticide-based barrier strategies can be utilized to reduce exposure to vector bites. Indeed, some of these approaches (i.e. insecticide-treated bed nets [ITN] and indoor-residual spraying [IRS]), represent keystone interventions for malaria control in endemic countries. They have been shown to provide substantial protection against malaria, including a significant reduction in all-cause childhood mortality (53-55). Of the two, this statement will only address in detail the use of ITN since IRS is applied by professionals in an endemic setting, and hence is outside the sphere of control for most travellers. However, for long-term travellers, expatriates, persons spending significant time in rural areas of risk, etc., a preference for accommodations or areas that are subject to IRS would not be unreasonable. For further information on IRS, readers are referred to the WHOPES (37), which provides information on IRS testing (56), and an up-to-date listing of approved IRS products (57). Importantly, IRS is not considered an alternative to ITN, but rather a complement, i.e. ITN are recommended whether or not IRS has been done. In addition to ITN, several other insecticide-based PPM strategies are available of which insecticide-treated clothing will be considered in some detail by this statement. 


\section{BED NETS}

1. Though little work has been done that specifically evaluates the utility of ITN for travellers, there are robust data to show that they provide significant protection against malaria amongst residents of endemic areas (e.g., 50\% reduction in uncomplicated malaria episodes) (53). CATMAT considers these data to be sufficient to make a strong recommendation that all travellers to foreign destinations endemic or epidemic for $A A D$ should use ITN. ITN are also recommended to provide protection against peridomestic bugs that transmit pathogens (e.g., triatomids) or that cause nuisance (e.g., bed bugs).

2. While ITN and related products (portable insecticidetreated netting) are typically deployed at night, they should be used whenever and wherever appropriate, including when resting indoors during the daytime and to protect children in cribs or strollers.

3. In Canada, insecticide treatments of bed nets fall under the regulatory control of the PMRA. Excepting products for military use, there are no current Canadian ITNrelated registrations, nor is there a specific policy that permits their sale in Canada for use abroad. Nevertheless, ITN can be obtained from some Canadian travel health clinics and other domestic and international suppliers. While a Canadian-registered ITN would be preferred, CATMAT does not consider it likely that registration will occur in the proximate future. However, the World Health Organization, through WHOPES, offers a process by which their safety and efficacy can be evaluated (37;58). In this respect, the WHOPES recommends specific insecticide formulations for treatment of conventional ITN (Appendix 5) $(59 ; 60)$ and recommends specific products (Appendix 6) (61) that have met their criteria (62) as long-lasting insecticidetreated nets $(\mathrm{LN})$. The latter represent a specific category of ITN that have met very stringent performance endpoints (e.g., field efficacy that persists for three or more years, maintenance of efficacy through 20 or more launderings). CATMAT considers that the WHOPES program is robust and recommends that bed nets should be selected based on a full or interim recommendation from the WHOPES, whether referenced against insecticide formulation (59) or specific LN product (61).

4. Several ITN or ITN treatments (e.g., Insect Shield ${ }^{\circledR}$ ), including LN (i.e. Pramex ${ }^{\circledast / D u r a t i o n}{ }^{\circledast}$ Nets; US EPA registration number 73049-433; nets are based on Olyset ${ }^{\circledR}$ technology), have been registered by the US EPA. Where these ITN are based on technologies for which there is a WHOPES recommendation (e.g., Olyset ${ }^{\circledast}$, Appendix 6), they are preferred over: products without an US EPA registration; or with a WHOPES recommendation, but not an EPA registration. Should ITN eventually be registered in Canada, a similar algorithm would apply, with a preference for Canadian registered products over US-registered products.

5. There are many different types of ITN available internationally, and manufacturing standards might not all be similarly exacting. For this reason, CATMAT recommends use of nets that are registered in Canada or the US and/or where the supplier/manufacturer can provide documentation to assure that WHOPES specifications have been met. Of note, some bed nets are marketed as $L N$ without having been so designated by WHOPES. CATMAT recommends that such products not be used or marketed as LN.

6. To minimize exposure to pesticides that might occur through spills or improper treatment of nets, CATMAT recommends that travellers use pre-treated nets rather than nets that they treat themselves. Where such is not possible, the WHOPES treatment/re-treatment guidelines should be followed (63).

7. For the majority of travellers, conventional ITNs should provide sufficiently long-lasting protection. However, where travel to a risk area is frequent and/or is expected to be for a long period (e.g., six months or greater), LNs might offer some advantage.

8. In some areas, the mosquito vectors of malaria have resistance to the insecticides (i.e. pyrethroids) that are currently used to treat ITN. It is not clear what the impact of such resistance is, or will be $(17 ; 18)$. At this time, aside from using additional and complementary techniques as already discussed in this statement, CATMAT does not have any specific recommendations related to use of insecticide-treated materials where resistance has been documented.

\section{CLOTHING TREATMENTS}

9. Insecticide-treated clothing (ITC) have been shown to protect against the bites of arthropods (64-67) and there also is evidence that they can protect against AAD (68). Use of ITC is therefore recommended for protection against AAD. ITC products currently registered in Canada contain permethrin and are limited to military use. However, many permethrin-based ITC products are available for civilian use in the US. They generally are available as a formulation that contains $0.5 \%$ permethrin and that the consumer applies to their own clothing, or as clothing that has been pre-treated to a level of $0.52 \%$ permethrin weight/weight. These approaches differ in that the latter approach is labelled to provide protection through tens of washes whereas the $0.5 \%$ product typically protects through several washes. Both are 
available from major US online retailers, and should be obtainable for personal use by Canadian consumers ${ }^{1}$ (69). For all treated garments or garment treatments, users should adhere to instructions provided on the label. As for topical repellents and ITN, until such time as ITC are registered in Canada, US EPA registered products are preferred over those available in other non-Canadian jurisdictions

10. To optimize protection against bites, ITC should be used in combination with an appropriate repellent product $(66 ; 70)$, preferably long-lasting, such that skin is near to completely protected, (i.e. apply topical repellent to exposed skin that is not covered by ITC).

11. For certain vectors, ITC are considered relatively more important. For example, ITC are thought to provide excellent protection against the bites of the ticks that transmit Borrelia burgdorferi, the causative agent of Lyme disease (67). There also are data to suggest that treated clothing protected military personnel against scrub typhus during WWII (71).

\section{OTHER INSECTICIDE PRODUCTS}

12. There are a variety of other insecticide-based approaches that are purported to control vectors and/ or nuisance arthropods like bed bugs. They include insecticide coils that are burned, insecticide vaporisers, aerosols and space sprays, and insecticide treated sheets. Many of these have been critical interventions

\section{Ineffective PPM}

There are many products that are marketed as effective PPM interventions. However, for some of these, there is not sufficient scientific evidence to support claims of efficacy and/or safety. Examples include electronic (ultrasonic) devices (75;76), wristbands, neckbands, and ankle bands impregnated with repellents (40), electrocuting devices during historic malaria control campaigns. For example, house fumigation with various products was used as part of an integrated strategy to control/eliminate malaria vectors during the construction of the Panama Canal and to rid Brazil of the African malaria vector A. gambiae (72;73). However, some of these approaches involve indoors release of relatively large doses of insecticide and hence are less likely to meet current regulatory standards for safety. Others, for example currently approved thermal vaporisers in Canada and the US, are limited by the paucity of data demonstrating their public health efficacy. Finally, while presumably efficacious against bed bugs and perhaps malaria vectors (74), products such as treated sheets are likely associated with increased insecticide exposure due to enhanced contact between the skin and the treated item.

CATMAT did not carry out a thorough literature review on these alternative approaches. Hence, it does not have a high degree of confidence in its assessment, but nevertheless recommends that the above-listed approaches not be used for prevention of AAD or nuisance bites. This determination is based on several factors: uncertainty about the safety profile of some of these interventions, uncertainty about their efficacy or the availability of alternatives that have demonstrated efficacy and acceptable safety profiles (e.g., ITN, ITC and topical repellents).

(75;77), odour-baited mosquito traps (78-80), the Citrosa plant $(78 ; 81 ; 82)$, oral vitamin B1 (83), and skin moisturizers that do not contain an approved repellent active ingredient (40). CATMAT recommends that these interventions not be used for protection against arthropod bites and related $A A D$.

\footnotetext{
1 Pest Control Products Regulations. Section 3.1.f. "The following pest control products are exempt from the application of the Act... a pest control product, other than an organism, that is imported into Canada primarily for use by the importer in or around the home, if the quantity being imported is not more than $500 \mathrm{~g}$ or $500 \mathrm{~mL}$ and the value of the quantity imported is not more than $\$ 100^{\prime \prime}(69)$.
} 


\section{APPENDIX 1. Summary information for some important arthropod vectors (84-88)}

\begin{tabular}{|c|c|c|}
\hline Vector & Disease caused & Peak biting times and areas \\
\hline Anopheles mosquitos & $\begin{array}{l}\text { Filariasis } \\
\text { Malaria }\end{array}$ & $\begin{array}{l}\text { Usually bite between sunset and sunrise. } \\
\text { Peak biting hours may vary. Some species } \\
\text { prefer to bite indoors, while others prefer } \\
\text { outdoors. }\end{array}$ \\
\hline Aedes mosquitos & $\begin{array}{l}\text { Dengue fever } \\
\text { Filariasis } \\
\text { Yellow fever }\end{array}$ & $\begin{array}{l}\text { Can bite throughout the day, often outside, } \\
\text { but some important vectors bite inside. }\end{array}$ \\
\hline Culex mosquitos & $\begin{array}{l}\text { Filariasis } \\
\text { Japanese encephalitis } \\
\text { West Nile virus }\end{array}$ & $\begin{array}{l}\text { Usually bite between sunset and sunrise, } \\
\text { often outdoors, but sometimes indoors. }\end{array}$ \\
\hline Mansonia mosquitos & Filariasis & Usually bite at night, mostly outdoors. \\
\hline Midges & $\begin{array}{l}\text { Mansonellosis } \\
\text { Oropouche fever }\end{array}$ & Can bite throughout day, usually outdoors \\
\hline Ticks & $\begin{array}{l}\text { Anaplasmosis } \\
\text { Babesiosis } \\
\text { Crimean-Congo hemorrhagic fever } \\
\text { Ehrlichioses } \\
\text { Lyme disease } \\
\text { Powassan encephalitis } \\
\text { Q fever } \\
\text { Rocky Mountain spotted fever } \\
\text { Tick-borne encephalitis } \\
\text { Tick-borne relapsing fever }\end{array}$ & $\begin{array}{l}\text { Widely dispersed in forest vegetation, } \\
\text { meadows, and grassy environments; wait } \\
\text { on grasses or branches of low bushes for } \\
\text { passing hosts. Some species are more } \\
\text { aggressive and actively search out } \\
\text { their host(s). }\end{array}$ \\
\hline Fleas & $\begin{array}{l}\text { Murine typhus } \\
\text { Plague } \\
\text { Tularemia }\end{array}$ & $\begin{array}{l}\text { Found indoors and outdoors, often } \\
\text { associated with a specific type of host, } \\
\text { but will feed on a variety of mammals } \\
\text { (including humans). }\end{array}$ \\
\hline Body lice & $\begin{array}{l}\text { Epidemic typhus } \\
\text { Louse-borne relapsing fever } \\
\text { Trench fever }\end{array}$ & $\begin{array}{l}\text { Usually found in clothing, except when } \\
\text { feeding on human host. }\end{array}$ \\
\hline Sand flies & $\begin{array}{l}\text { Leishmaniasis } \\
\text { Sand fly fever }\end{array}$ & $\begin{array}{l}\text { Usually bite at night; many bite outdoors, } \\
\text { but some also feed indoors. }\end{array}$ \\
\hline Black flies & Human onchocerciasis & $\begin{array}{l}\text { Usually bite in the daytime, outdoors, } \\
\text { in areas around rivers or streams. }\end{array}$ \\
\hline Deer and horse flies (Tabanids) & $\begin{array}{l}\text { Loiasis } \\
\text { Tularemia }\end{array}$ & $\begin{array}{l}\text { Active during the daytime outdoors, } \\
\text { often during the sunniest hours; rarely } \\
\text { feed indoors. }\end{array}$ \\
\hline Tsetse flies (Glossina) & African Trypanosomiasis & $\begin{array}{l}\text { Usually active during the daytime (though } \\
\text { some important vector species are active at } \\
\text { dusk or dawn) and usually bite outdoors. }\end{array}$ \\
\hline Triatomine/ reduviid bugs & American Trypanosomiasis & $\begin{array}{l}\text { Active at night and usually feed indoors on } \\
\text { human blood. }\end{array}$ \\
\hline
\end{tabular}

NOTE: References $(87 ; 88)$ in English and French, respectively, provide a series of detailed tables related to vectors, the diseases that they are associated with, and risk areas. 


\section{APPENDIX 2. Strength and Quality of Evidence (10)}

\begin{tabular}{l|l}
\multicolumn{2}{l}{ Categories for the Strength of Each Recommendation } \\
\hline Category & Definition \\
\hline A & Good evidence to support a recommendation for use. \\
\hline B & Moderate evidence to support a recommendation for use. \\
\hline C & Poor evidence to support a recommendation for or against use. \\
\hline D & Moderate evidence to support a recommendation against use. \\
\hline E & Good evidence to support a recommendation against use. \\
\hline
\end{tabular}

\begin{tabular}{l|l}
\multicolumn{2}{l}{ Categories for the Quality of Evidence on Which Recommendations are Made } \\
\hline Grade & Definition \\
\hline I & Evidence from at least one properly randomized, controlled trial. \\
\hline II & $\begin{array}{l}\text { Evidence from at least one well-designed clinical trial without randomization, from cohort or case-controlled analytic } \\
\text { studies, preferably from more than one centre, from multiple time series, or from dramatic results in uncontrolled } \\
\text { experiments. }\end{array}$ \\
\hline III & $\begin{array}{l}\text { Evidence from opinions or respected authorities on the basis of clinical experience, descriptive studies, or reports of } \\
\text { expert committees. }\end{array}$ \\
\hline
\end{tabular}

\section{APPENDIX 3. Evidence-based medicine (EBM) recommendations}

\section{Recommendations}

EBM rating (10)

\section{Avoiding arthropods:}

1. Avoid travelling to risk areas during the season(s) when transmission of AAD is most likely.

2. Reduce exposure by avoiding times or places when/where vectors are known to be active (e.g., by staying indoors during peak activity periods, minimizing exposure in rural areas or other habitats associated with specific vectors).

\section{Physical barriers:}

1. Use screening on doors and windows, close eaves, eliminate holes in roofs and walls and close other gaps to protect $\mathrm{BI}$ work and accommodation areas against vectors.

2. Wear appropriate clothing (e.g., full length, loose fitting and light-coloured garments).

\section{Chemical barriers:}

1. Use topical repellents that are registered in Canada on exposed areas of skin to prevent arthropod bites and to reduce the risk of $A A D$.

i. Repellents that contain DEET (20-30\%) or icaridin (20\%) should be the first choice for adults.

ii. Repellents that contain icaridin (20\%) should be the first choice for children aged six months to twelve years. Repellents containing age-appropriate concentrations of DEET should be considered as a second choice for children aged six months to twelve years.

iii. Repellents that contain p-menthane-3,8-diol should be considered second-choice topical repellents for adults and children aged three years or older.

iv. Other active ingredients currently registered in Canada (e.g., citronella, soybean oil) are not widely available and/ or do not provide sufficiently long protection times against bites, and are not recommended for use to protect travellers against the bites of vectors.

v. For travel outside of Canada to endemic/epidemic areas, the risk for arthropod-associated diseases (AAD) likely outweighs the risk of an adverse reaction to DEET or icaridin. In such situations and if vectors cannot be otherwise excluded (e.g., through use of insecticide-treated netting), use of up to $10 \%$ DEET or $10 \%$ icaridin should be considered for infants under six months of age.

vi. If biting is noted before the re-application interval indicated on the label has expired, reapply repellent. BII

vii. Where there is interest in minimizing the amount of repellent used, apply at times of the day where vectors are most active and exposure is more likely (e.g., when leaving a bed net in the morning and in the late afternoon). 


\section{Recommendations}

EBM rating (10)

viii. Where possible, choose PPM to suit each traveller's needs (e.g., a cream, spray or liquid topical repellent, to enhance the likelihood of product use).

ix. Do not use repellent and sunscreen combination products.

CIII

EII

$x$. It is preferable to apply sunscreen first and allow it to penetrate the skin before applying repellent. Where this is not possible, apply both products even if such is done contemporaneously.

\section{Insecticide barriers:}

1. For long-term travellers, expatriates, persons spending significant time in rural areas of risk, etc., a preference for accommodations or areas that are subject to indoor residual spraying is reasonable.

\section{Bed nets:}

1. Use insecticide-treated nets (ITN) for protection against arthropod bites and related diseases.

i. While ITN and related products (portable insecticide-treated netting) are typically deployed at night, they should be used whenever and wherever appropriate, including when resting indoors during the daytime or to protect children in cribs and strollers.

ii. Where possible, bed nets should be selected based on a PMRA or EPA registration and a full or interim recommendation from the World Health Organization Pesticide Evaluation Scheme (WHOPES).

iii. Use products manufactured where there is greater assurance of quality (e.g., in western countries or where the supplier/manufacturer can provide documentation to assure that WHOPES specifications have been met).

iv. Some products are marketed as LN without having been so designated by WHOPES. CATMAT cannot evaluate the veracity of such claims, and hence recommends that these products not be used or marketed as long-lasting ITN (LN).

v. To minimize exposure to pesticides that might occur through spills or improper treatment of nets, use pre-treated nets rather than nets that you treat yourself.

vi. Where travel is frequent and/or is expected to be for a long period (e.g., six months or greater) use LN.

vii. Use ITN to reduce the bites from nuisance arthropods and to protect against snake bites.

CIII

$\left(\frac{100}{20}\right.$

CIII

Al

Al

All

All

CIII

DIII

DIII

CIII

Clothing treatments:

1. Use insecticide-treated clothing (ITC) to protect against the bites of vectors and nuisance arthropods.

BII

i. To optimize protection against bites, ITC should be used in combination with an appropriate repellent product, preferably long-lasting, such that skin is near to completely protected, i.e. apply topical repellent to exposed skin that is not covered by ITC.

ii. Until such time as ITC are registered in Canada for civilian use, use ITC that have been registered by the United States Environmental Protection Agency (US EPA).

\section{Other insecticide products:}

1. CATMAT recommends against use of/reliance on other insecticide-based approaches such as insecticide coils that are burned, insecticide vaporizers, aerosols and space sprays, and insecticide-treated sheets.

2. CATMAT recommends against use of insect personal protection measures that are ineffective, or that have not been convincingly shown to be efficacious against arthropod vectors and related diseases. They include:

- Electronic (ultrasonic) devices

- Wristbands, neckbands, and ankle bands impregnated with repellents

- Electrocuting devices ("bug zappers")

- Odour-baited mosquito traps

- Citrosa plant (geranium houseplant)

- Orally administered vitamin B1

- Skin moisturizers that do not contain an approved repellent active ingredient. 
APPENDIX 4. Protection time estimates for various concentrations of DEET

\begin{tabular}{|c|c|c|c|c|c|c|}
\hline \multirow{3}{*}{$\%$ DEET } & \multicolumn{6}{|c|}{ Complete protection time } \\
\hline & \multicolumn{2}{|c|}{ Mean } & \multicolumn{2}{|c|}{ Lower residual } & \multicolumn{2}{|c|}{ Upper residual } \\
\hline & Minutes & Hours* & Minutes & Hours* & Minutes & Hours* \\
\hline 5 & 110 & 2 & 76 & 1.5 & 144 & 2.5 \\
\hline 10 & 214 & 3.5 & 158 & 2.5 & 270 & 4.5 \\
\hline 15 & 276 & 5 & 208 & 3.5 & 344 & 5.5 \\
\hline 20 & 319 & 5.5 & 243 & 4 & 395 & 6.5 \\
\hline 25 & 352 & 6 & 269 & 4.5 & 469 & 8 \\
\hline 30 & 380 & 6.5 & 281 & 5 & 469 & 8 \\
\hline
\end{tabular}

*Rounded off to the nearest half hour

SOURCE: Health Canada, Pest Management Regulatory Agency RRD 2002-01 (41)

\section{APPENDIX 5. WHO recommended insecticide products treatment of mosquito nets for malaria vector control}

1. Conventional treatment:

\begin{tabular}{l|l|l}
\hline Insecticide & Formulation ${ }^{1}$ & Dosage $^{2}$ \\
\hline Alpha-cypermethrin & SC 10\% & $20-40$ \\
\hline Cyfluthrin & EW 5\% & 50 \\
\hline Deltamethrin & SC 1\%; WT 25\%; and WT 25\% + binder ${ }^{3}$ & $15-25$ \\
\hline Etofenprox & EW 10\% & 200 \\
\hline Lambda-cyhalothrin & CS 2.5\% & $10-15$ \\
\hline Permethrin & EC 10\% & $200-500$ \\
\hline
\end{tabular}

2. Long-lasting treatment:

\begin{tabular}{l|l|l}
\hline Product name & Product type & Status of WHO recommendation \\
\hline$I^{C O N}{ }^{\circledR} \mathrm{MAXX}$ & $\begin{array}{l}\text { Lambda-cyhalothrin } 10 \% \mathrm{CS}+\text { binder } \\
\text { Target dose of } 50 \mathrm{mg} / \mathrm{m}^{2}\end{array}$ & Interim \\
\hline
\end{tabular}

${ }^{1} \mathrm{EC}=$ emulsifiable concentrate; $\mathrm{EW}=$ emulsion, oil in water; $\mathrm{CS}=$ capsule suspension; $\mathrm{SC}=$ suspension concentrate; $\mathrm{WT}=$ water dispersible tablet

2 Milligrams of active ingredient per square metre of netting

${ }^{3} \mathrm{~K}-\mathrm{O}$ TAB $1-2-3^{\circledR}$

NOTES: (1) WHO recommendations on the use of pesticides in public health are valid ONLY if linked to WHO specifications for their quality control. WHO specifications for public health pesticides are available on the WHO homepage on the Internet at: www.who.int/whopes/quality/en

(2) for an updated list, access the WHOPES website (www.who.int/whopes).

SOURCE: World Health Organization Pesticide Evaluation Scheme (WHOPES) (59) 


\section{APPENDIX 6. WHO recommended long-lasting (LN) insecticidal mosquito nets}

\begin{tabular}{|c|c|c|c|}
\hline Product name & Product type & $\begin{array}{l}\text { Status of WHO } \\
\text { recommendation }\end{array}$ & $\begin{array}{l}\text { Status of } \\
\text { publication of } \\
\text { WHO specification }\end{array}$ \\
\hline DawaPlus $^{\circledR} 2.0$ & Deltamethrin coated on polyester & Interim & Published \\
\hline Duranet $^{\circledR}$ & Alpha-cypermethrin incorporated into polyethylene & Interim & Published \\
\hline Interceptor $^{\circledR}$ & Alpha-cypermethrin coated on polyester & Full & Published \\
\hline LifeNet ${ }^{\circledR}$ & Deltamethrin incorporated into polypropylene & Interim & Published \\
\hline MAGNet ${ }^{\mathrm{TM}}$ & Alpha-cypermethrin incorporated into polyethylene & Interim & Published \\
\hline Netprotect ${ }^{\circledR}$ & Deltamethrin incorporated into polyethylene & Interim & Published \\
\hline Olyset $^{\circledR}$ & Permethrin incorporated into polyethylene & Full & Published \\
\hline Olyset ${ }^{\circledast}$ Plus & Permethrin and PBO incorporated into polyethylene & Interim & Pending \\
\hline PermaNet $^{\circledR} 2.0$ & Deltamethrin coated on polyester & Full & Published \\
\hline PermaNet ${ }^{\circledR} 2.5$ & Deltamethrin coated on polyester with strengthened border & Interim & Published \\
\hline PermaNet $^{\circledR} 3.0$ & $\begin{array}{l}\text { Combination of deltamethrin coated on polyester with strengthened } \\
\text { border (side panels) and deltamethrin and PBO incorporated into } \\
\text { polyethylene (roof) }\end{array}$ & Interim & Published \\
\hline Royal Sentry ${ }^{\circledR}$ & Alpha-cypermethrin incorporated into polyethylene & Interim & Published \\
\hline Yorkool ${ }^{\circledR}$ LN & Deltamethrin coated on polyester & Full & Published \\
\hline
\end{tabular}

\section{NOTES:}

1. Reports of the WHOPES Working Group Meetings should be consulted for detailed guidance on use and recommendations. These reports are available on the WHO homepage on the Internet at: www.who.int/whopes/recommendations/wgm/en; and

2. WHO recommendations on the use of pesticides in public health are valid ONLY if linked to WHO specifications for their quality control. WHO specifications for public health pesticides are available on the WHO homepage on the Internet at: www.who.int/whopes/quality/newspecif/en

3. For an updated list, access the WHOPES website (www.who.int/whopes)

SOURCE: World Health Organization Pesticide Evaluation Scheme (WHOPES) (61) 


\section{References}

(1) Krzywinski J, Grushko OG, Besansky NJ. Analysis of the complete mitochondrial DNA from Anopheles funestus: an improved dipteran mitochondrial genome annotation and a temporal dimension of mosquito evolution. Mol Phylogenet Evol 2006;39(2):417-23.

(2) Statement on dengue. An Advisory Committee Statement (ACS). CCDR 2009;35(ACS-2):1-12.

(3) Kiszewski A, Mellinger A, Spielman A, Malaney P, Sachs SE, Sachs J. A global index representing the stability of malaria transmission. Am J Trop Med Hyg 2004;70(5):486-98.

(4) Pates $\mathrm{H}$, Curtis C. Mosquito behavior and vector control. Annu Rev Entomol 2005;50:53-70.

(5) Klun JA, Strickman D, Rowton E, Williams J, Kramer M, Roberts $D$, et al. Comparative resistance of Anopheles albimanus and Aedes aegypti to $\mathrm{N}, \mathrm{N}$-diethyl-3-methylbenzamide (Deet) and 2-methylpiperidinyl-3-cyclohexen-1-carboxamide (Al3-37220) in laboratory human-volunteer repellent assays. J Med Entomol 2004;41(3):418-22.

(6) Moore SJ, Debboun M. History of insect repellents. In: Debboun M, Francis S, Strickman D, editors. Insect repellents: Principles, methods and uses. CRC Press; 2007. p. 3-29.

(7) Maia MF, Moore SJ. Plant-based insect repellents: a review of their efficacy, development and testing. Malar J 2011;10 Suppl 1:S11.

(8) Kitchen LW, Lawrence KL, Coleman RE. The role of the United States military in the development of vector control products, including insect repellents, insecticides, and bed nets. J Vector Ecol 2009;34(1):50-61.

(9) Goodyer LI, Croft AM, Frances SP, Hill N, Moore SJ, Onyango SP, et al. Expert review of the evidence base for arthropod bite avoidance. J Travel Med 2010;17(3):182-92.

(10) Committee to Advise on Tropical Medicine and Travel (CATMAT). Evidence-based medicine. CCDR 1994;20:145-7.

(11) Committee to Advise on Tropical Medicine and Travel (CATMAT). Statement on personal protective measures to prevent arthropod bites. CCDR 2005;31(ACS-4).
(12) Literature retrieval system [Internet].United States: Armed Forces Pest Management Board. c1962- [cited 2011 Apr 24]. Available from: www.afpmb.org

(13) Croft AM. Malaria: prevention in travellers. Clin Evid (Online ) 2010;pii: 0903.

(14) Balshem $H$, Helfand M, Schunemann HJ, Oxman AD, Kunz R, Brozek J, et al. GRADE guidelines: 3. Rating the quality of evidence. J Clin Epidemiol 2011;64(4):401-6.

(15) Pest Management Regulatory Agency [homepage on the Internet]. 2011 [cited 2011 Apr 24]. Available from: www.hc-sc.gc.ca/cps-spc/pest/index-eng.php

(16) United States Environmental Protection Agency. Office of Pesticide Programs [homepage on Internet]. 2011 [cited 2011 Apr 24]. Available from: www.epa.gov/pesticides

(17) Djenontin A, Chabi J, Baldet T, Irish S, Pennetier C, Hougard JM, et al. Managing insecticide resistance in malaria vectors by combining carbamate-treated plastic wall sheeting and pyrethroid-treated bed nets. Malar J 2009;8:233.

(18) Ranson H, N'guessan R, Lines J, Moiroux N, Nkuni Z, Corbel V. Pyrethroid resistance in African anopheline mosquitoes: what are the implications for malaria control? Trends Parasitol 2011;27(2):91-8.

(19) Committee to Advise on Tropical Medicine and Travel (CATMAT). Canadian recommendations for the prevention and treatment of malaria among international travellers. CCDR 2009;(35 Suppl 1):1-82.

(20) Lindsay SW, Emerson PM, Charlwood JD. Reducing malaria by mosquito-proofing houses. Trends Parasitol 2002;18(11):510-4.

(21) Lindsay SW, Jawara M, Paine K, Pinder M, Walraven GE, Emerson PM. Changes in house design reduce exposure to malaria mosquitoes. Trop Med Int Health 2003;8(6):512-7.

(22) Kirby MJ, Ameh D, Bottomley C, Green C, Jawara M, Milligan PJ, et al. Effect of two different house screening interventions on exposure to malaria vectors and on anaemia in children in The Gambia: a randomised controlled trial. Lancet 2009;374(9694):998-1009. 
(23) Njie M, Dilger E, Lindsay SW, Kirby MJ. Importance of eaves to house entry by anopheline, but not culicine, mosquitoes. J Med Entomol 2009;46(3):505-10.

(24) Chappuis F, Sharma SK, Jha N, Loutan L, Bovier PA. Protection against snake bites by sleeping under a bed net in southeastern Nepal. Am J Trop Med Hyg 2007;77(1):197-9.

(25) Christophers S. Mosquito repellents; being a report of the work of the mosquito repellent inquiry, Cambridge, 1943-5. J Hyg 1947;45:176-231.

(26) Schoepke A, Steffen F, Norman G. Effectiveness of personal protection measures against mosquito bites for malaria prophylaxis in travelers. J Travel Med 1998 Dec;5(4):182-92.

(27) Joy RJ. Malaria in American troops in the South and Southwest Pacific in World War II. Med Hist 1999;43(2):192-207.

(28) Wormser GP, Dattwyler RJ, Shapiro ED, Halperin JJ, Steere AC, Klempner MS, et al. The clinical assessment, treatment, and prevention of lyme disease, human granulocytic anaplasmosis, and babesiosis: clinical practice guidelines by the Infectious Diseases Society of America. Clin Infect Dis 2006;43(9):1089-134.

(29) Public Health Agency of Canada. Lyme disease fact sheet [Internet]. 2010 [cited 2011 Apr 24]. Available from: www.phac-aspc.gc.ca/id-mi/ lyme-fs-eng.php

(30) Syed Z, Leal WS. Mosquitoes smell and avoid the insect repellent DEET. Proc Natl Acad Sci U S A 2008;105(36):13598-603.

(31) Liu C, Pitts RJ, Bohbot JD, Jones PL, Wang G, Zwiebel LJ. Distinct olfactory signaling mechanisms in the malaria vector mosquito Anopheles gambiae. PLoS Biol 2010;8(8).

(32) Bohbot JD, Dickens JC. Insect repellents: Modulators of mosquito odorant receptor activity. PLoS One 2010;5(8):e12138.

(33) United States Environmental Protection Agency Office of Chemical Safety and Pollution Prevention. Product performance test guidelines: Insect repellents to be applied to human skin [Internet]. 2010 [cited 2011 Apr. 24]. Report No: OPPTS 810.3700. Available from: www.epa.gov/hsrb/files/ meeting-materials/jun-23-2010-public-meeting/ Repellent_Guideline_5-13-2010\%5B1\%5D.pdf
(34) Hill N, Lenglet A, Arnez AM, Carneiro I. Plant based insect repellent and insecticide treated bed nets to protect against malaria in areas of early evening biting vectors: double blind randomised placebo controlled clinical trial in the Bolivian Amazon. BMJ 2007;335(7628):1023.

(35) Centers for Disease Control and Prevention. Updated information regarding insect repellents [Internet]. 2008 [cited 2011 Apr 24].

Available from: www.cdc.gov/ncidod/dvbid/ westnile/RepellentUpdates.htm

(36) Zielinski-Gutierrez E, Wirtz RA, Nasci RS. The Pre-Travel Consultation. Protection against mosquitoes, ticks, and other insects and arthropods. CDC health information for international travel 2012. Atlanta: U.S. Department of Health and Human Services, Public Health Service; 2011. p. 86-9.

(37) World Health Organization Pesticide Evaluation Scheme [homepage on Internet]. 2011 [cited 2011 Apr 24]. Available from: www.who.int/whopes/en

(38) World Health Organization Pesticide Evaluation Scheme. Report of the fourth WHOPES working group meeting: review of: IR3535; KBR3023; (RS)-methoprene $20 \%$ EC, pyriproxyfen 0.5\% GR; and lambdacyhalothrin 2.5\% CS [Internet]. 2001 [cited 2011 Apr 24]. Report No.: WHO/CDS/WHOPES/2001.2. Available from: http://apps.who.int/ctd/whopes/docs/ Report4thWHOPESWGM.pdf

(39) Pest Management Regulatory Agency. Proposed acceptability for continuing registration: re-evaluation of citronella oil and related active compounds for use as personal insect repellents. Ottawa: Health Canada; 2004. Report No.: PACR2004-36.

(40) Fradin MS, Day JF. Comparative efficacy of insect repellents against mosquito bites. $\mathrm{N}$ Engl J Med 2002;347(1):13-8.

(41) Pest Management Regulatory Agency Submission Coordination and Documentation Division.

Re-evaluation decision document: personal insect repellents containing DEET ( $\mathrm{N}, \mathrm{N}$-diethyl-m-toluamide and related compounds) [Internet]. Ottawa: Health Canada; 2002 Apr 15 [cited 2011 Apr 24]. Report No.: RRD2002-01. Available from: http://dsp-psd.pwgsc. gc.ca/Collection/H113-12-2002-1E.pdf 
(42) Schofield S, Tepper M, Gadawski R. Laboratory and field evaluation of the impact of exercise on the performance of regular and polymer-based deet repellents. J Med Entomol 2007;44(6):1026-31.

(43) Barnard D, Xue R. Biometrics and behaviour in mosquito repellent assays. In: Debboun M, Francis $\mathrm{S}$, Strickman D, editors. Insect repellents: Principles, methods and uses. CRC Press; 2007. p.111-24.

(44) Granett P. Studies of mosquito repellents, I. Test procedure and method of evaluating test data. J Econ Entomol 1940;33(3):563-5.

(45) Vickery JP, Tribble DR, Putnam SD, McGraw T, Sanders JW, Armstrong AW, et al. Factors associated with the use of protective measures against vectorborne diseases among troops deployed to Iraq and Afghanistan. Mil Med 2008;173(11):1060-7.

(46) Keystone JS. Compliance with travel health recommendations. In: Dupont HI, Steffen F, editors. Textbook of travel medicine and health. London: B.C. Decker Inc.; 2001.

(47) Alon D, Shitrit P, Chowers M. Risk behaviors and spectrum of diseases among elderly travelers: $A$ comparison of younger and older adults. J Travel Med 2010;17(4):250-5.

(48) Webb CE, Russell RC. Insect repellents and sunscreen: implications for personal protection strategies against mosquito-borne disease. Aust N Z J Public Health 2009;33(5):485-90.

(49) Montemarano AD, Gupta RK, Burge JR, Klein K. Insect repellents and the efficacy of sunscreens. Lancet 1997;349(9066):1670-1.

(50) Chen T, Burczynski FJ, Miller DW, Gu X. Percutaneous permeation comparison of repellents picaridin and DEET in concurrent use with sunscreen oxybenzone from commercially available preparations. Pharmazie 2010;65(11):835-9.

(51) Wang T, Gu X. In vitro percutaneous permeation of the repellent DEET and the sunscreen oxybenzone across human skin. J Pharm Pharm Sci 2007;10(1):17-25.

(52) Gu X, Wang T, Collins DM, Kasichayanula S, Burczynski FJ. In vitro evaluation of concurrent use of commercially available insect repellent and sunscreen preparations. Br J Dermatol 2005;152(6):1263-7.
(53) Lengeler C. Insecticide-treated bed nets and curtains for preventing malaria. Cochrane Database Syst Rev 2004;(2):CD000363

(54) Gamble C, Ekwaru JP, ter Kuile FO. Insecticidetreated nets for preventing malaria in pregnancy. Cochrane Database Syst Rev 2006;(2):CD003755.

(55) Pluess B, Tanser FC, Lengeler C, Sharp BL. Indoor residual spraying for preventing malaria. Cochrane Database Syst Rev 2010;(4):CD006657.

(56) World Health Organization Pesticide Evaluation Scheme. Guidelines for testing mosquito adulticides for indoor residual spraying and treatment of mosquito nets [Internet]. 2006. [cited 2011 Apr 24]. Report No.: WHO/CDS/NTD/WHOPES/GCDPP/2006.3. Available from: http://whqlibdoc.who.int/hq/2006/WHO_CDS_ NTD_WHOPES_GCDPP_2006.3_eng.pdf

(57) World Health Organization Pesticide Evaluation Scheme. WHO recommended insecticides for indoor residual spraying against malaria vectors [Internet]. 2009 [updated 2009 Oct; cited 2011 Apr 24]. Available from: www.who.int/whopes/Insecticides_IRS_ Malaria_09.pdf

(58) World Health Organization Pesticide Evaluation Scheme. A generic risk assessment model for insecticide treatment and subsequent use of mosquito nets [Internet]. 2004 [cited 2011 Apr 24]. Report No.: WHO/CDS/WHOPES/GCDPP/2004.6; WHO/PCS/04.1. Available from: http://whqlibdoc. who.int/hq/2004/WHO_PCS_04.1.pdf

(59) World Health Organization Pesticide Evaluation Scheme. WHO recommended insecticide products treatment of mosquito nets for malaria vector control [Internet]. 2011 [updated 2007 Dec; cited 2011 Apr 18]. Available from: www.who.int/whopes/ Insecticides_ITN_Malaria_ok3.pdf

(60) World Health Organization Pesticide Evaluation Scheme. WHO specifications for pesticides used in public health [Internet]. 2011 [cited 2011 Apr 24]. Available from: www.who.int/whopes/quality/ newspecif/en

(61) World Health Organization Pesticide Evaluation Scheme. WHO recommended long-lasting insecticidal mosquito nets [Internet]. 2012 updated 2012 July; [cited 2012 July 9]. Available from: www.who.int/whopes/Long_lasting_insecticidal_nets_ Jul_2012.pdf 
(62) World Health Organization Pesticide Evaluation Scheme. Guidelines for laboratory and field testing of long-lasting insecticidal mosquito nets [Internet]. 2005 [cited 2011 Apr 24]. Report No.: WHO/CDS/ WHOPES/GCDPP/2005.11. Available from: http://whqlibdoc.who.int/hq/2005/WHO_CDS_ WHOPES_GCDPP_2005.11.pdf

(63) World Health Organization Pesticide Evaluation Scheme. Instructions for treatment and use of insecticide-treated mosquito nets [Internet]. 2002 [cited 2011 Apr 24]. Available from: www.who.int/malaria/publications/atoz/who_ cds_rbm_2002_41/en

(64) Schreck CE, Posey K, Smith D. Durability of permethrin as a potential clothing treatment to protect against blood-feeding arthropods. J Econ Entomol 1978;71(3):397-400.

(65) Schreck CE, Carlson DA, Weidhaas DE, Posey K, Smith $D$. Wear and aging tests with permethrintreated cotton-polyester fabric. J Econ Entomol 1980;73(3):451-3.

(66) Schreck CE, Haile DG, Kline DL. The effectiveness of permethrin and deet, alone or in combination, for protection against Aedes taeniorhynchus. Am J Trop Med Hyg 1984;33(4):725-30.

(67) Vaughn MF, Meshnick SR. Pilot study assessing the effectiveness of long-lasting permethrin-impregnated clothing for the prevention of tick bites. Vector Borne Zoonotic Dis 2011; [Epub ahead of print].

(68) Soto J, Medina F, Dember N, Berman J. Efficacy of permethrin-impregnated uniforms in the prevention of malaria and leishmaniasis in Colombian soldiers. Clin Infect Dis 1995;21(3):599-602.

(69) Department of Justice Canada. Pest control products regulations SOR/2006-124. 2006 [updated 2010 Jun 3; cited 2011 Apr 24]. Available from: http://laws-lois. justice.gc.ca/PDF/SOR-2006-124.pdf

(70) Rowland M, Freeman T, Downey G, Hadi A, Saeed M. DEET mosquito repellent sold through social marketing provides personal protection against malaria in an area of all-night mosquito biting and partial coverage of insecticide-treated nets: a case-control study of effectiveness. Trop Med Int Health 2004;9(3):343-50.
(71) Welt LG. Use of dimethylphthalate impregnated clothing as protection against scrub typhus. Am J Trop Med Hyg 1947 Mar;27(2):221-4.

(72) Gladwell M. Fred Soper and the global malaria eradication programme. J Public Health Policy 2002;23(4):479-97.

(73) Patterson R. Dr. William Gorgas and his war with the mosquito. CMAJ 1989;141(6):596-7, 599.

(74) Rowland M, Durrani N, Hewitt S, Mohammed N, Bouma M, Carneiro I, et al. Permethrin-treated chaddars and top-sheets: appropriate technology for protection against malaria in Afghanistan and other complex emergencies. Trans R Soc Trop Med Hyg 1999;93(5):465-72.

(75) Surgeoner GA, Helson BV. A field evaluation of electrocutors for mosquito control in southern Ontario. Proc Entomol Soc Ontario 1977;108:53-7.

(76) Enayati AA, Hemingway J, Garner P. Electronic mosquito repellents for preventing mosquito bites and malaria infection. Cochrane Database Syst Rev 2007;(2):CD005434.

(77) Nasci RS, Harris CW, Porter CK. Failure of an insect electrocuting device to reduce mosquito biting. Mosquito News 1983;43(2):180-4.

(78) Jensen T, Lampman R, Slamecka MC, Novak RJ. Field efficacy of commercial antimosquito products in Illinois. J Am Mosq Control Assoc 2000;16(2):148-52.

(79) Burkett DA, Lee WJ, Lee KW, Kim HC, Lee HI, Lee JS, et al. Light, carbon dioxide, and octenol-baited mosquito trap and host-seeking activity evaluations for mosquitoes in a malarious area of the Republic of Korea. J Am Mosq Control Assoc 2001;17(3):196-205.

(80) Kitau J, Pates H, Rwegoshora TR, Rwegoshora D, Matowo J, Kweka EJ, et al. The effect of Mosquito Magnet Liberty Plus trap on the human mosquito biting rate under semi-field conditions. J Am Mosq Control Assoc 2010;26(3):287-94.

(81) Matsuda BM, Surgeoner GA, Heal JD, Tucker AO, Maciarello MJ. Essential oil analysis and field evaluation of the citrosa plant "Pelargonium citrosum" as a repellent against populations of Aedes mosquitoes. J Am Mosq Control Assoc 1996 Mar;12(1):69-74. 
(82) Cilek JE, Schreiber ET. Failure of the "mosquito plant", Pelargonium x citrosum 'van Leenii', to repel adult Aedes albopictus and Culex quinquefasciatus in Florida. J Am Mosq Control Assoc 1994;10(4):473-6.

(83) Khan AA, Maibach HI, Strauss WG, Fenley WR. Vitamin B1 is not a systemic mosquito repellent in man. Trans St Johns Hosp Dermatol Soc 1969:55(1):99-102.

(84) Durden LA, Mullen GR, editors. Medical and Veterinary Entomology. New York: Academic Press; 2002.

(85) Canadian Department of National Defence Anthropod-borne Disease Surveillance Manual. GDG Environment; 2006.
(86) Rozendaal JA. Vector control: methods for use by individuals and communities. Geneva: 1977.

(87) Personal Protection Against Vectors working groups. Personal protection against biting insects and ticks. Parasite 2011;18:93-11.

(88) La Société de Médecine des Voyages et la Société Française de Parasitologie. Reccomandations de bonne practique: Protetion personnelle antivectorielle- texte court. 2010. [cited 2011 May 6]. Available from: www.medecine-voyages.fr/ publications/ppavtextecourt.pdf 